\title{
Reflexões sobre a gestão de processos de desinstitucionalização
}

\author{
Reflections on the management of deinstitutionalization process
}

Marcela Adriana da Silva Lucena ${ }^{1}$

Adriana Falangola Benjamin Bezerra ${ }^{1}$

${ }^{1}$ Departamento de Medicina Social, Centro de Ciências da Saúde, Universidade Federal de Pernambuco. Avenida Prof. Moraes Rêgo, s/n. Cidade Universitária.

Centro de Ciências da Saúde, bloco D, 1 andar. 50670-420 Recife PE.

marcelaslucena@gmail.com

\begin{abstract}
This study addresses mental health and, based on a conceptual review, offers considerations on the management of deinstitutionalization processes regarding individuals interned in long-stay psychiatric institutions. Elements concerning asylum formation and logic are discussed, along with the mechanisms necessary for the effective change in paradigm and practices, with deinstitutionalization and psychosocial rehabilitation as the core issues. Reflections are offered regarding management actions committed to the psychosocial model, linking such actions to the application of the components of care and going beyond the articulation of the tools of mental health policy. Theoretical reflection offers suggestions referring to the qualification processes of mental health professionals, deinstitutionalization in the management of the Unified Health System and tripartite action with co-accountability in actions and financing. The final considerations recognize the bureaucratic obstacles in the public realm and propose facing these challenges as a management challenge, along with processes of change that can radically commit to the lives of people, thereby broadening the discussion to the ethical realm.
\end{abstract}

Key words Management, Deinstitucionalization, Rehabilitation, Care
Resumo O tema a ser tratado neste artigo encontra-se dentro do campo da saúde mental e, mediante revisão conceitual, realiza considerações sobre a gestão de processos de desinstitucionalização de pessoas com internação psiquiátrica de longa permanência, abordando elementos acerca da formação e lógica asilar, assim como sobre a engrenagem necessária para a efetivação da mudança de seu paradigma e de suas práticas, considerando a desinstitucionalização e a reabilitação psicossocial como eixos centrais. Realiza reflexão sobre a ação gerencial comprometida com o modelo psicossocial, atrelando a mesma à aplicação dos componentes do cuidado, indo para além da articulação das ferramentas da política de saúde mental. A partir da reflexão teórica, traz indicativos referentes aos processos de qualificação dos trabalhadores de saúde mental, à desinstitucionalização como pauta para pactuação de gestão no SUS e à ação tripartite com corresponsabilização nas ações e financiamento. Nas considerações finais reconhece os obstáculos burocráticos no âmbito público e propõe como desafio gerencial o enfrentamento destes e a indução de processos de mudança que possam radicalmente se comprometer com a vida das pessoas, ampliando a dimensão da discussão para o campo ético.

Palavras-chave Gestão, Desinstitucionalização, Reabilitação, Cuidado 


\section{Introdução}

Este artigo propõe discutir algumas questões acerca de processos de desinstitucionalização que consideramos importantes para o diálogo com os gestores, especialmente aqueles que têm em seus territórios de atuação instituições psiquiátricas a serem desconstruídas.

Para isso, aborda inicialmente aspectos em torno da instituição asilar, seus significados e repercussões, e, posteriormente, discute o processo de desconstrução do manicômio em contrapartida à construção de uma rede territorial. Por fim, realiza algumas reflexões sobre a gestão de processos de desinstitucionalização.

\section{A instituição asilar e suas repercussões}

A engrenagem do desmonte de uma instituição manicomial concomitantemente à montagem de uma rede territorial são questões chaves postas no debate da saúde mental no Sistema Único de Saúde (SUS), uma vez que requer o desenho de práticas de gestão integradas, estratégias terapêuticas e intervenções sociais ligadas diretamente aos usuários.

O primeiro passo é compreender que significados traz a instituição manicomial e por que a necessidade do seu desmonte, considerando suas repercussões negativas e devastadoras na vida das pessoas.

Ao tentar compreender a loucura e a sua relação estabelecida com a sociedade ao longo do tempo, é possível remeter-se aos inscritos de Foucault ${ }^{1}$ sobre este assunto. Até meados da Revolução Francesa em 1789, a loucura fazia parte do universo daqueles descritos como "expurgos" da sociedade que precisavam ser controlados e regenerados a favor de uma ordem social a ser instituída.

Com a influência do positivismo e assunção da ciência em contraposição ao poder do rei e de Deus, a loucura vai se tornado objeto de estudo da medicina e ganhando dentro da sociedade um espaço próprio, com as realizações de Philippe Pinel em 17932.

Forma-se o hospital psiquiátrico constituído em si mesmo como o próprio remédio para a pretendida cura: o retorno do alienado à realidade e o seu enquadramento às regras da sociedade. Com a medicina vai sendo elaborada uma nosografia médica e se formatando um saber fundante para a psicopatologia e a consequente consagração da loucura como doença mental. O hospital psiquiátrico vai então se instituindo como instrumento único e exclusivo para trata- mento e se ancorando no isolamento para fins de constituição do conhecimento científico ${ }^{3}$.

Neste sentido, ao mesmo tempo, vão se elaborando formas de abordagens e tratamentos mediante definição de uma rotina asilar e de uma relação de autoridade que vai cristalizando a concepção de tutela como a principal moldagem para a ligação entre médico e paciente no campo da psiquiatria, baseada inicialmente em um conjunto de estratégias terapêuticas disciplinares, a saber: ordens, castigos e trabalho.

À medida que o isolamento vai se consolidando como princípio de tratamento, contribui para produção da necessidade de medidas de proteção, dada a noção de periculosidade que vai sendo atribuída ao louco e legitimada pela instituição asilar.

Pode-se melhor compreender esta instituição à luz das teorizações a respeito das instituições totais que, segundo Goffman ${ }^{4}$, são aquelas capazes de destituir-se de sua subjetividade aqueles a ela submetidos, baseadas em relações de poder e de controle. É o que se chama, mediante uma construção processual calcada em aparatos coercitivos, de mortificação do eu.

"O enfermo, logo que internado no hospital, é definido como doente, e todas as suas ações, participações e reações são interpretadas e explicitadas em termos de doença. Logo, a vida institucional se baseia sobre a negação de valores aprioristicamente definida, para o internado, que é considerado irreversivelmente objetivado pela doença, o que justifica, no plano prático-institucional, a relação objetivante com ele instaurada"5.

Dadas todas as repercussões dos processos de institucionalização, a história revela que a própria sociedade se encarrega de levantar questionamentos sobre a instituição que ela mesma legitimou a partir do nascimento de novas teorias e experiências humanas devastadoras - especialmente após a segunda guerra mundial, tempo que apresentava uma demanda político-social na perspectiva de rever as instituições, de cuidar das pessoas fragilizadas pela guerra e de reestruturar a sociedade.

A psiquiatria nesta época entra como um campo a ser repensado que não traz no primeiro momento a necessidade de rever a concepção de loucura, mas as práticas institucionais voltadas para a mesma.

É o que alguns teóricos denominam como reformas psiquiátricas: as que propuseram uma remodelagem institucional (Psiquiatria Institucional na França e a Comunidade Terapêutica na Inglaterra); as que incorporaram a comunidade como 
ponto central para o desenvolvimento do tratamento, tornando o asilo como complementar (Psiquiatria de Setor na França e a Psiquiatria Preventiva nos EUA) e as que questionaram a própria psiquiatria: seus saberes e suas práticas, propondo uma ruptura com a instituição asilar por um viés fortemente ideológico e político (Antipsiquiatria na Inglaterra e Psiquiatria Democrática na Itália $)^{6}$.

Essas reformas psiquiátricas foram responsáveis pela criação de novas configurações epistemológicas e assistenciais no campo da psiquiatria, tendo a experiência italiana privilegiado os eixos da desinstitucionalização e reabilitação psicossociais, determinantes para experiência brasileira e fundamentais para a engrenagem colocada como objeto de estudo.

\section{A engrenagem: de uma intervenção de aprisionamento a uma proposta de cuidado}

A superação de instituições de "natureza total" requer uma ruptura com o sistema coercitivo e sua própria problematização ${ }^{5}$. Nesta perspectiva, essa transformação vai além de um processo de desospitalização, do qual concebemos como uma política de altas hospitalares e redução gradual de número de leitos sem construção efetiva de um sistema e de uma lógica que substitua o aparato hospitalar. A suposta, e necessária, superação da instituição asilar demanda efetivamente o acolhimento e a invenção de novas formas de cuidar que remetam a um processo de responsabilização pelos sujeitos.

Para que possa ocorrer uma real mudança estrutural na assistência, a desmontagem do aparato institucional deve passar, necessariamente, por uma proposta de desinstitucionalização.

Com base na Reforma Italiana, se aborda o tema como "um processo social complexo que tende a mobilizar como atores os sujeitos sociais envolvidos, que tende a transformar as relações de poder entre os pacientes e as instituições, que tende a produzir estruturas de saúde mental que substituem inteiramente a internação em hospital psiquiátrico e que nascem da desmontagem e reconversão de recursos materiais e humanos que estavam ali depositados"7.

Nesta perspectiva, a desinstitucionalização não é um procedimento ou um conjunto de ações no sentido de reverter a assistência psiquiátrica tradicional, mas um processo contínuo que consiste na transformação dessa instituição e numa reorganização sanitária dos projetos, perpassando pela dimensão da relação terapêutica (das concepções e práticas de tratamento) à dimensão da construção de uma nova política no campo (das concepções e práticas da ação política $)^{7}$.

A separação do "fenômeno doença" da "existência dos sujeitos" e do "seu corpo social" produziu um vácuo, induzindo a construção de um conjunto de aparatos científicos, legislativos, administrativos, materializados pela instituição, reafirmando e legitimando a doença. Percebe-se uma tendência das unidades institucionais de atender as demandas a partir de suas competências, perdendo a dimensão da integralidade, e de alguma forma reafirmando os sujeitos naquilo que ela institui como verdade acerca da compreensão dos mesmos.

O paradigma da desinstitucionalização, então, propõe desmontar essa dinâmica com todos os seus aparatos para retomar o contato com a existência dos sujeitos.

Trata-se de um rompimento com a busca incisiva e histórica pelo entendimento etiológico da loucura enquanto doença e de uma reproposição de solução centrada na existência do sujeito e sua relação com o meio social, formatando a ação terapêutica na perspectiva de transformação institucional em prol da invenção da saúde e reprodução social do paciente.

A partir das leituras de vários autores acerca do tema em curso, especialmente Rotelli et al. ${ }^{7} \mathrm{e}$ Albuquerque $^{8}$, se pode dizer que o processo de desinstitucionalização implica na mobilização de todos os atores envolvidos no sistema de ação institucional (trabalhadores, gestores, familiares, pacientes e outros possíveis agentes) e na transformação das relações de poder entre a instituição e das pessoas por ela assistida.

Essa transformação começa das microrrelações: a mudança da relação de tutela pela de contratualidade, na qual a troca é o foco - quem cuida passa a "tomar encargo" no sentido da responsabilização e ao mesmo tempo, reconhece o sujeito como protagonista da sua própria história, independente da sua condição psicopatológica.

Os autores ainda referem que a desinstitucionalização implica na utilização de todo aparato interno da instituição (seus recursos) para sua própria decomposição e construção de uma nova instituição, o que gera mudanças: uma nova forma de administrar os recursos públicos (processos de trabalho, relações interpessoais, dinâmica institucional, entre outros); a centralização do trabalho terapêutico no sujeito e a construção de estruturas externas substitutivas à internação no manicômio com base no território, no trabalho em rede e no processo de responsabilização ${ }^{7,8}$. 
O eixo da desinstitucionalização e suas proposições são referentes a processos inacabados e que exigem perpétua inovação do jogo institucional. A sua concretude advém da singularização do olhar e do cuidado a partir da reconstrução das práticas mediante produção de estratégias balizadas na proposta de reabilitação psicossocial.

Esta ideia é referenciada pela Reforma Psiquiátrica Brasileira, que visa à reconstrução da concepção de loucura, enfocando a questão do sofrimento psíquico e repensando as formas de cuidado. A proposta é um redirecionamento do modelo assistencial, antes centrado no hospital psiquiátrico, para uma atenção integrada, em rede, baseada no território e também provocando transformações nas dimensões culturais e legais. Em outras palavras, ela visa sustentar as pessoas com suas diferenças na sociedade.

Estamos essencialmente falando de uma mudança de paradigma do doente ao sujeito, da relação de tutela à de contrato, do tratamento ao cuidado. Uma exigência permanente de intervir diferente.

Ayres $^{9}$ dialoga que para a construção do cuidado é necessário debruçar-se "sobre as raízes e significados de adoecimentos em sua condição de obstáculos coletivamente postos a projetos de felicidade humana e, de forma articulada, da disposição socialmente dada das tecnologias e serviços disponíveis para sua superação".

Ainda segundo o autor ${ }^{9}$, para sua realização, a reconstrução da prática de cuidado necessita, "de esforços coletivos e pragmáticos de um processo público de interação entre diversas pretensões, exigências e condições de validade das diversas proposições e interesses em disputa”.

Esses esforços no campo da saúde mental podem ser traduzidos pelas tentativas de efetivar as mudanças de concepções, superando o modelo asilar e consolidando o modelo psicossocial com produção de estratégias de reabilitação.

Antes de nomear de forma propositiva as novas possibilidades de intervenção, se faz necessário tomar o conceito empregado de reabilitação psicossocial.

A partir das ideias de Saraceno ${ }^{10}$, a reabilitação psicossocial é vista como estratégia global. O mesmo aponta que todas as pessoas têm um determinado nível contratual que faz com que utilize no seu cotidiano o seu poder de negociação, alguns mais, outros menos, a partir de uma habilidade construída ao longo da vida que perpassa por vários cenários legitimados pela sociedade (família, escola, trabalho, círculo de amizades) e apresentados dinamicamente em contínuo processo de mudança. A esse cenário, o autor chama espaço de troca, espaço social, onde as relações se estabelecem.

"[...] todos nós atuamos em três grandes cenários: cenário habitat, cenário mercado e o cenário de trabalho... onde acontece o desenrolar das cenas, das histórias, dos efeitos, de todos os elementos: dinheiro, afetos, poderes, símbolos, etc" 10 .

A questão é: como concretamente operacionalizar esta noção, especialmente junto a pessoas em situação de maior vulnerabilidade ou em desvantagem social?

Vasconcelos ${ }^{11}$, ao colocar as abordagens psicossociais na direção contrária às abordagens clínicas convencionais, demonstra que alguns elementos devem ser considerados como objeto da reabilitação psicossocial, a saber: o conhecimento crítico da realidade no âmbito das relações de poder estabelecidas na sociedade; a luta pela transformação das condições concretas de vida, de moradia e trabalho e de reprodução social dos usuários; o amplo reconhecimento das necessidades específicas dos indivíduos e grupos sociais, aumentando a oferta e a universalização a dispositivos adequados de atenção e cuidado.

O autor ${ }^{11}$ sinaliza ainda como importantes focos da reabilitação a mudança dos serviços, das políticas sociais e dos saberes científicos e profissionais envolvidos no processo psicossocial; a ampliação e a defesa dos direitos civis, políticos e sociais dos usuários, assim como a reinvenção de modos de viver no sentido de maior criatividade e inovação. Aponta como ideia central a oferta de subsídios concretos para que indivíduos e grupos sociais adquiram a criticidade à sua condição construída, ampliando o rol de possibilidades e a aceitação das diferenças existenciais na vida social e cultural, exatamente na direção contrária da adaptação e ajustamento.

Consideramos que Ayres ${ }^{9}$, explorando as heterodoxias terapêuticas ao abordar a questão da humanização da assistência, traz algumas contribuições para a proposição do cuidado que podem ser aproveitadas no campo psicossocial em relação à materialização das intervenções. Quando aponta a necessidade dos serviços de saúde desenvolverem ações para além deles mesmos, cita: "apoio à escolarização e aquisição de competências profissionais, desenvolvimento de talentos e vocações, atividades físicas e de vivências corporais, atividades de lazer e socialização, promoção e defesa dos direitos, proteção legal e policial, integração a ações de desenvolvimento comunitário e participação política”. 
Kinoshita $^{12}$ ao escrever a respeito dos processos construtivos de autonomia e do poder contratual aponta que, dada a situação das pessoas institucionalizadas, uma das formas potentes de construir este cuidado é emprestando ao usuário o poder contratual do técnico, o fazer junto, até que ele construa paulatinamente, de forma singular e possível, a sua trajetória.

Essa ideia se aplica bem aos processos de reabilitação de pessoas com alto grau de vulnerabilidade social e com histórias de institucionalização, nos quais a prática de cuidado consiste em reconstruir pessoas ${ }^{13}$.

Como reconstituir pessoas? Ativar para a vida, trazer à tona a potência de vida, criando espaços para o exercício do desejo das pequenas coisas às grandes realizações: ter um lar - um lugar de pertencimento, desenvolver de forma autônoma e possível suas atividades da vida diária, tomar decisões, ou seja, construir um cotidiano capaz de criar pontes para habitar a cidade.

Neste sentido, é fundamental explorar as possibilidades de desenvolver projetos de gestão comprometidos com projetos de vida; de transformar a dureza das diretrizes normativas e financeiras da política de saúde numa ação concreta e objetiva, mas, também capaz de produzir vida.

Há necessidade de certa engenharia que requer do gestor, em processos complexos como os de desinstitucionalização, a utilização dos recursos institucionais e ao mesmo tempo, o desenvolvimento de uma forma de gestar comprometida com a mudança de paradigma.

\section{A gestão de processos de desinstitucionalização: da dureza das estruturas à necessária reconstrução das práticas}

Como moldar o arcabouço de estratégias interventivas institucionais para planejar e produzir ações com alma? Que entrelinhas podem ser desenhadas num processo duro como fechar leitos e abrir novos serviços, correr contra o tempo e escalar obstáculos burocráticos?

Uma possibilidade de enfrentamento de tal questão pode ser a incorporação dos componentes de uma prática de cuidado, imprescindíveis para abordagem de problemas complexos no intuito de ampliar as chances de desenvolver um raciocínio gerencial coerente com o paradigma psicossocial. Eis um ensaio da aplicação destes componentes pensando a desconstrução de um hospital psiquiátrico e a constituição de uma rede de cuidados territoriais, à exigência de:
Conhecer

- O hospital psiquiátrico no território - a representação que tem, o uso dele feito pela população e como a rede de serviços se porta em relação a ele.

- A população de longa permanência: de onde são as pessoas originalmente, quantas são, quem são, suas histórias, sua condição clínica e seus vínculos familiares e comunitários, caso existam.

- Os atores em jogo: os opositores da Reforma Psiquiátrica, os declaradamente defensores, os potenciais aliados, os aliados, os trabalhadores, os familiares, e tantos outros.

- A rede: seus recursos, sua dinâmica, suas fragilidades e suas potências.

- A Política de Saúde Mental: seus paradigmas e ferramentas de gestão.

Acolher a demanda

Fazendo referência às ideias desenvolvidas por Teixeira ${ }^{14}$ e transportando-as para a dimensão da gestão, consideramos que acolher a demanda está associado à capacidade de escutar os atores envolvidos com os problemas e a si mesmo diante das diferentes situações, estabelecendo uma relação interativa e dialógica de forma permanente.

Responsabilizar-se

Tomar para si, na condição de gestor, o desafio de articular a construção das respostas. Tomar encargo, ir ao encontro ${ }^{15}$. No âmbito da gestão isso significa olhar, dirigir a atenção, priorizar, colocar na pauta, articulando para isso todos os recursos no sentido da construção das respostas.

Na perspectiva da desinstitucionalização, a responsabilização deve se dar mediante o compromisso com a desconstrução de instituições manicomiais, mas prioritariamente, com a vida das pessoas lá internadas, ou seja, com a oferta de serviços que, como uma solução substitutiva aos hospitais, possa abarcar o cuidado psicossocial das pessoas em seus territórios existenciais. Tal decisão significa dirigir investimentos para a criação de dispositivos que deem conta das necessidades das pessoas com a implantação direta ou articulação de serviços para que estas possam acessar de forma adequada o apoio importante para sua reabilitação.

\section{Decidir}

A decisão possibilita acontecer. Tomar uma decisão é "tender a uma posição amplamente determinada por uma situação que precede o momento da decisão, mas, que se reestrutura para e pelo sujeito da decisão a partir do momento em que, junto ao outro, atualiza seu projeto existencial na decisão tomada" 


\section{Compartilhar}

Partilhar algo com alguém. Fazendo uma alusão à ideia de Sérgio Arouca ao falar da Reforma Sanitária como civilizatória ${ }^{16}$, se pode dizer que realizar processos de desinstitucionalização é apostar numa proposta civilizatória através de repercussões singulares produzidas para os sujeitos e para a sociedade, uma vez que acolher a diferença no meio social é construir um caminho de tolerância, de reconhecimentos da positividade das diferenças, de ser mais humana.

Considerando que a dimensão das repercussões de processos de desinstitucionalização se expande para a vida nas suas várias facetas, o caminho para atingi-la é pelo compartilhamento de responsabilidades, de ideias, de ações e de recursos. É fundamental transportar a elaboração de uma ação intersetorial para a pauta de trabalho cotidiana com o envolvimento dos vários setores nos processos de desinstitucionalização e nos cuidados dispensados no território. Só coletivamente se consegue construir soluções de enfrentamento para grandes problemas.

Produzir ação com capacidade de responder a problemas imediatos (à sobrevivência e à diminuição de riscos e agravos) e a construir estruturas capazes de mudar a realidade.

Intervir simultaneamente dentro e fora do hospital, criando viabilidade para os sonhos e os projetos numa costura que abarque uma variedade de retalhos formando uma colcha inacabada, mas, ao mesmo tempo sintonizada pelas cores e formato. Pôr em prática o poder.

Considerando os elementos acima como essenciais para fazer gestão, se faz necessário também utilizar os recursos existentes para a viabilidade dos processos. Hoje, especialmente a partir da Lei $10.216 / 01^{17}$, se tem referências claras que, materializadas em portarias e recomendações, dadas suas potências e limites, possibilitam ao gestor desenvolver:

Processos regulatórios e de planificação de leitos junto aos hospitais psiquiátricos: o Programa de Reestruturação da Assistência Hospitalar (PRH) - Portarias MS/GM 52 ${ }^{18}$ e 53/04 ${ }^{19}$ e o Programa Nacional de Avaliação Hospitalar (PNASH/Psiquiatria) - Portaria MS/GM 251/02 ${ }^{20}$.

Projetos voltados diretamente para o processo de desinstitucionalização e reinserção social, a saber: O Programa de Volta Para Casa - Lei Nacional 10.708/0321 que institui o auxílio-reabilitação para pacientes acometidos de transtornos mentais egressos de internações; os Serviços Residenciais Terapêuticas - Portaria MS/GM 106/0022; Projetos de Geração de Renda - Portaria MS/GM
1.169/0523 e os Centros de Convivência - Portaria $396 / 05^{24}$.

Projetos voltados para a assistência: Saúde Mental na Atenção Primária - Portarias MS/GM $154 / 08^{25}$ e $2843 / 10^{26}$; Leitos em Hospitais Gerais Portarias MS/GM 189/9127, 1.612/05 28 e 2.842/10 ${ }^{29}$ e os Centros de Atenção Psicossocial (CAPS) Portaria MS/GM 336/02 ${ }^{30}$. Importante ressaltar que embora algumas das portarias aqui mencionadas sejam direcionadas à atenção de pessoas que fazem uso de álcool e outras drogas, entendemos que fazer referências a estas é importante por compor o escopo tanto da atenção primária como dos leitos em hospital geral dentro da configuração da assistência.

O grande desafio dos tempos atuais é a urgência em acelerar os processos de desinstitucionalização, haja vista que o Ministério da Saúde ${ }^{31}$ aponta uma estimativa de que $35 \%$ da população internada em hospitais psiquiátricos no país são de longa permanência, ou seja, ainda esperam pela possibilidade de retomar a vida e outras tantas circulam no território, demandando cuidados que sejam efetivos e leais ao mandato da inclusão social.

Para isso, é imprescindível aprimorar as ferramentas de gestão de forma tal que possam dar conta da complexidade de um processo de desinstitucionalização e responder às demandas advindas do percurso de desmontagem do hospital psiquiátrico à organização da rede territorial.

Para finalizar este artigo, se apontam três considerações como pontos importantes para esta revisão. Não há pretensão de aprofundá-las ou até mesmo responder a todas as lacunas da política, mas, principalmente de provocar inquietações e discussões para a busca de maturação dos elementos que se constituem muitas vezes como obstáculos nos diferentes âmbitos de gestão no sentido de garantir o seu desenho coerente com o paradigma psicossocial.

Consideramos fundamental o desenvolvimento de uma proposta de educação permanente comprometida com o eixo da desinstitucionalização, ou seja, a instrumentalização dos nossos trabalhadores para operar o cuidado conforme as referências da Reforma Psiquiátrica, refletidas na legislação em saúde mental. Uma qualificação que minimize os riscos de cristalização de certo tecnicismo e construa crescentemente a capacidade de reflexão sobre o sentido "do fazer", ampliando também, a capacidade de construir práticas orientadas pelas reais demandas dos usuários e seus familiares. Uma proposta que prime por uma metodologia dialógica entre os princí- 
pios teóricos, da política e as diferentes realidades na perspectiva de construir um conhecimento aplicado.

Para isso, se faz necessária uma revisão da lógica normativa e de financiamento. Embora o financiamento das propostas de formação esteja contemplado nos Planos de Educação Permanente de forma descentralizada ${ }^{32}$, o que se considera um avanço, ainda assim, há uma dificuldade real, a nosso ver, de operacionalização dos recursos financeiros para o desenvolvimento de propostas de formação nas várias áreas.

Um segundo aspecto importante a ser considerado é a necessidade de inclusão dos processos de desinstitucionalização na dimensão de pactuações de responsabilidade e compromissos no âmbito da gestão do SUS. Muitas dessas iniciativas ficam a mercê de conjunturas políticas que definem a intensidade do investimento.

Campos $^{33}$ ao discutir sobre os desafios para a sustentabilidade do SUS enfatiza a importância da criação de mecanismos organizacionais capazes de definir responsabilidades (macro e microsanitária) dos entes federados, com estabelecimento do encargo com compromissos e cofinanciamento na relação intergovernamental. Isso nos remete a pensar na necessária formação de indicadores de saúde mental que possibilitem a entrada do tema na pauta dos gestores e induza a formação de uma agenda de compromissos a fim de nortear as pactuações.

Desta forma, sugerimos alguns conteúdos que consideramos importantes para a construção destes indicadores: erradicação de população de longa permanência em hospitais psiquiátricos, regulação local das internações psiquiátricas, erradicação de macro-hospitais nos diferentes territórios e oferta de ações de saúde mental extra-hospitalares.

Outro elemento fundamental no âmbito da política é o financiamento. Retomando a ideia de Campos $^{33}$, podemos sinalizar como imprescindível desenhar para a saúde mental uma proposta de financiamento tripartite com percentuais e diretrizes claras quanto à contrapartida de cada ente federado e que possa contemplar um projeto territorial, rompendo com a lógica de alocação de recursos fragmentada por serviços ou editais. Um financiamento que se produza a partir de uma agenda de compromissos e responsabilidades, respeitando as diferentes realidades e necessidades.

\section{Considerações finais}

A constituição do hospital psiquiátrico além de cristalizar determinadas concepções sobre a loucura ao longo do tempo determinou formas de operar com este fenômeno que ainda influencia a sociedade. Isso fica claro quando ao lidar com as questões de organização de rede territorial de saúde mental, muitas vezes, sermos indagados sobre os ricos de manter as pessoas fora do hospital e sobre a necessidade deste em sua recuperação.

É como se houvesse um reconhecimento de que é preciso haver cuidados mais humanizados, no entanto, paradoxalmente, fosse necessária a existência de algum dispositivo na retaguarda para assegurar que a saída do hospital não dando certo ou tendo situações de crise, terá um lugar protegido para onde encaminhar as pessoas.

A pergunta que nos cabe é: não dando certo o quê? Protegido para quem?

Observamos que a produção do cuidado está diretamente ligada às lógicas que a instituem, e, desta forma, as instituições efetivam o sentido de sua existência e função. Goffman ${ }^{4}$ retrata isso quando teoriza sobre as instituições totais.

Parece ser necessário ultrapassar essa barreira que vai para além dos muros, uma barreira que paira no imaginário, com pensamentos e ideias muitas vezes ainda imbuídas de preconceito ou restritas a um viés de compreensão: apenas a perspectiva psiquiátrica ou a concepção de que estruturas humanizadas são suficientes para garantir os processos de desinstitucionalização.

Pensar eficazes estruturas substitutivas ao manicômio é apostar numa nova forma de cuidar comprometida com a construção de autonomia e protagonismo das pessoas. É apostar que a sociedade pode aprender a tolerar a diferença e a lidar com os conflitos por ela produzidos. E o que é mais importante, ousar na condição de gestores ao efetivar a mudança de paradigma: abrir espaços para a realização de experiências vivas de desinstitucionalização e reabilitação psicossocial, ou seja, viabilizar.

No cenário estatal muitos são os obstáculos para desenvolver processos arrojados e transformadores, desde problemas estruturais de concepção, financiamento e organização burocrática da máquina institucional, até as advindas do excesso de demandas e carência de recursos que exigem continuamente trabalhar sobre situações de emergência.

De forma paradoxal, aos gestores, dependendo da sua sustentabilidade política num dado governo, se tem uma capacidade de poder e con- 
trole capaz de induzir processos de mudança e fazer o enfrentamento dos obstáculos referidos. Merhy $^{34}$ ao abordar este assunto sinaliza esta capacidade como: a de formular política na arena institucional, controlar financiamento público, fazer uso de aparato estatal, de induzir o uso de tecnologias, de criar mecanismos de acessibilidade aos prestadores, de produzir possibilidades governamentais oriundas das relações entre os diferentes atores, redefinindo permanentemente potências e regras.
A discussão colocada então perpassa pela dimensão ética: o que produzimos no ato de gerenciar e em que estão centradas as nossas prioridades? $\mathrm{O}$ ato de gerenciar implicará sempre disputa de projetos e requer para uma efetiva transformação de cenários certa flexibilidade e dinamismo no sentido de permear os elementos técnicos e não técnicos na constituição de uma sabedoria prática ${ }^{9}$.

Qual o sentido das nossas práticas? Por quê? E para quê? O que nos faz suscitar movimentos?

\section{Colaboradores}

MAS Lucena trabalhou na concepção, delineamento e redação do artigo e AFB Bezerra na revisão crítica e aprovação da versão a ser publicada. 


\section{Referências}

1. Foucault M. História da loucura na Idade Clássica. São Paulo: Perspectiva; 1978.

2. Amarante P, organizador. Saúde mental, políticas e instituições. V. 2. Rio de Janeiro: EAD, Fiocruz; 2003.

3. Amarante P, organizador. Loucos pela vida - a trajetória da reforma psiquiátrica no Brasil. Rio de Janeiro: SDE, ENSP; 1995.

4. Goffman E. Manicômios, prisões e conventos. 5a. Ed. São Paulo: Perspectiva; 1996.

5. Ongaro FB. Transformação Institucional e objetivos comuns. In: Basaglia F, organizador. A Instituição Negada: relato de um hospital psiquiátrico. 2a. Ed. Rio de Janeiro: Graal; 1985. p. 273-283.

6. Birman J, Costa JF. Organização de Instituições para uma psiquiatria comunitária. In: Amarante $\mathrm{P}$, organizador. Psiquiatria Social e Reforma Psiquiátrica. Rio de Janeiro: Fiocruz; 1988.

7. Rotelli F, Leonardis O, Mauri D. Desinstitucionalização: uma outra via. In: Nicácio MFS, organizadora. Desinstitucionalização. 2a. Edição. São Paulo: Hucitec; 2001.

8. Albuquerque P. Desinstitucionalização: notas sobre um processo de trabalho. Cadernos do IPUB 2006; XII(22):93-110.

9. Ayres JR. O cuidado, os modos de ser (do) humano e as práticas de saúde. Saúde e Sociedade 2004; 13(3):16-29.

10. Saraceno B. Reabilitação psicossocial: uma estratégia para a passagem do milênio. In: Pitta $A$, organizadora. Reabilitação psicossocial no Brasil. São Paulo: Hucitec; 1996. p. 13-18.

11. Vasconcelos EM. Pressupostos Teóricos e Produção do Conhecimento no Campo Psicossocial, em uma Perspectiva Popular Democrática. In: Vasconcelos EM. Abordagens Psicossociais: história, teoria e prática no campo. V. 1. São Paulo: Hucitec; 2008.

12. Kinoshita RT. Contratualidade e reabilitação psicossocial. In: Pitta A, organizadora. Reabilitação psicossocial no Brasil. São Paulo: Hucitec; 1996. p. 55-59.

13. Rotelli F. A Instituição Inventada. In: Nicácio MFS, organizadora. Desinstitucionalização. 2a. Edição. São Paulo: Hucitec; 2001.

14. Texeira R. O Acolhimento num serviço de saúde entendido como uma rede de conversações. In: Pinheiro R, Mattos RA, organizadores. Construção da integralidade: cotidiano, saberes e práticas em saúde. Rio de Janeiro: UERJ, IMS, Abrasco; 2003. p 89-112.

15. Dell'acqua G, Mezzina R. Resposta à crise. In: Delgado J, organizador. A Loucura na Sala de Jantar. São Paulo: Resenha Ltda; 1991. p 53-79.

16. Brasil. Ministério da Saúde, Conselho Nacional de Saúde. $12^{a}$ Conferência Nacional de Saúde - Conferência Sergio Arouca: manual; 2003, Brasília; 2003.

17. Brasil. Lei 10.216 de 06 de abril de 2001. Dispõe sobre a proteção e os direitos das pessoas portadoras de transtornos mentais e redireciona o modelo assistencial em saúde mental. Diário Oficial da União 2001; 06 abr.

18. Brasil. Ministério da Saúde (MS). Portaria 52 de 20 de janeiro de 2004. Institui o Programa da Assistência Psiquiátrica Hospitalar no SUS. Diário oficial da União 2004; 20 jan.
19. Brasil. Ministério da Saúde (MS). Portaria 53 de 01 de março de 2004. Estabelece nova classificação dos hospitais psiquiátricos prevista no Programa Anal de Reestruturação da Assistência Hospitalar. Diário oficial da União 2004; 20 jan.

20. Brasil. Ministério da Saúde (MS). Portaria 251 de 31 de janeiro de 2002. Estabelece diretrizes e normas para a assistência hospitalar em psiquiatria; reclassifica os hospitais psiquiátricos, definindo estrutura e porta de entrada das internações na rede SUS. Diário oficial da União 2002; 31 jan.

21. Brasil. Lei 10.708 de 31 de julho de 2003. Institui o auxílio-reabilitação psicossocial para pessoas com transtornos mentais egressas de internações de longa permanência. Diário Oficial da União 2003; 31 jul.

22. Brasil. Ministério da Saúde (MS). Portaria 106 de 11 de fevereiro de 2000. Cria os serviços residenciais terapêuticos no âmbito do Sistema de Saúde para o atendimento ao portador de transtornos mentais. Diário oficial da União 2000; 11 fev.

23. Brasil. Ministério da Saúde (MS). Portaria 1.169 de 07 de julho de 2005. Define linha de financiamento para projetos de geração de renda em saúde mental. Diário Oficial da União 2005; 07 jul.

24. Brasil. Ministério da Saúde (MS). Portaria 396 de 07 de julho. Cria os centros de convivência. Diário Oficial da União 2005; 07 jul.

25. Brasil. Ministério da Saúde (MS). Portaria 154 de 24 de janeiro de 2008. Institui o Núcleo de Apoio ao Saúde da Família - NASF. Diário Oficial da União 2008; 24 jan.

26. Brasil. Ministério da Saúde (MS). Portaria 2.843 de 21 de setembro de 2010. Cria o NASF 3. Diário Oficial da União 2010; 21 set.

27. Brasil. Ministério da Saúde (MS). Portaria 189 de 19 de novembro de 1991. Aprova grupo de procedimentos da tabela de SIH e SAI/SUS incluindo a normatização para atenção em saúde mental em hospitais gerais. Diário Oficial da União 1991; 19 nov.

28. Brasil. Ministério da Saúde (MS). Portaria 1.612 de 09 de setembro de 2005. Estabelece critérios para habilitação de serviços hospitalares de referência para álcool e outras drogas. Diário Oficial da União 2005; 09 set.

29. Brasil. Ministério da Saúde (MS). Portaria 2.842 de 20 de setembro de 2010. Aprova as Normas de Funcionamento e Habilitação dos Serviços Hospitalares de Referência para a Atenção Integral aos Usuários de Álcool e outras Drogas. Diário Oficial da União 2010; 20 set.

30. Brasil. Ministério da Saúde (MS). Portaria 336 de 19 de fevereiro de 2002. Estabelecem os Centros de Atenção Psicossocial (CAPS) nas suas modalidades e normatiza suas possíveis ações. Diário oficial da União 2002; 19 fev.

31. Brasil. Ministério da Saúde (MS). Relatório de Gestão 2003 - 2006. Saúde Mental no SUS: Acesso ao tratamento de mudança do modelo de atenção. Brasília: MS; 2007.

32. Brasil. Ministério da Saúde (MS). Saúde Mental no SUS as Novas Fronteiras da Reforma Psiquiátricarelatório de gestão 2007-2010. Brasília: MS; 2011. 
33. Campos GWS. Reforma política e sanitária: a sustentabilidade do SUS em questão? Cien Saude Colet 2007; 12(2):301-306.

34. Merhy EE. Um dos grandes desafios para os gestores do sus: apostar em novos modos de fabricar os modelos de atenção. In: Merhy EE, Magalhães Júnior HM, Rimoli J, Franco TB, Bueno WS, organizadores. Trabalho em Saúde: olhando e experienciando o SUS no cotidiano. Rio de Janeiro: Hucitec; 2002.

Artigo apresentado em 30/04/2011

Aprovado em 09/07/2011

Versão final apresentada em 30/07/2011 